\title{
TGF $\beta_{1}$ activates c-Jun and Erk I via $\alpha_{\mathbf{v}} \beta_{6}$ integrin Karsta Luettich ${ }^{1}$ and Christian Schmidt*2
}

\author{
Address: ${ }^{1}$ Department of Dermatology, Weill Medical College of Cornell University, 1300 York Avenue, New York, New York, 10021, USA and \\ ${ }^{2}$ Department of Surgical Oncology and Molecular Oncology, University of Texas M. D. Anderson Cancer Center, 1515 Holcombe Boulevard, \\ Houston, Texas 77030, USA \\ Email: Karsta Luettich - karsta.luettich@molecular-cancer.org; Christian Schmidt* - christian.schmidt@molecular-cancer.org \\ * Corresponding author
}

Published: 23 September 2003

Molecular Cancer 2003, 2:33
Received: 06 September 2003

Accepted: 23 September 2003

This article is available from: http://www.molecular-cancer.com/content/2/1/33

(C) 2003 Luettich and Schmidt; licensee BioMed Central Ltd. This is an Open Access article: verbatim copying and redistribution of this article are permitted in all media for any purpose, provided this notice is preserved along with the article's original URL.

\begin{abstract}
Transforming growth factor $\beta$ (TGF $\beta$ ) plays an important role in animal development and many cellular processes. A variety of cellular functions that are required for tumor metastasis are controlled by integrins, a family of cell adhesion receptors. Overexpression of $\alpha_{\mathrm{V}} \beta_{6}$ integrin is associated with lymph node metastasis of gastric carcinomas. It has been demonstrated that a full TGF $\beta_{1}$ signal requires both $\alpha_{v} \beta_{6}$ integrin and SMAD pathway. TGF $\beta_{1}$ binds to $\alpha_{v} \beta_{6}$ via the DLXXL motif, a freely accessible amino acid sequence in the mature form of TGF $\beta_{1}$. Binding of mature TGF $\beta_{1}$ to $\alpha_{v} \beta_{6}$ leads to immobilization and tyrosine phosphorylation of proteins, which are associated with focal adhesions, a hallmark of integrin-mediated signal transduction. Here, we show that binding of mature TGF $\beta$, recruits the mitogen-activated protein kinase kinase kinase I (MEKKI), a mediator of c-Jun activation, and the extracellular signaling-regulated kinase-I (ErkI) to focal adhesions. In addition, the $\mathrm{P} 2 \mathrm{I}$-activated kinase I (PAKI) is associated with focal adhesions and differentially phosphorylated upon TGF $\beta_{1}$ stimulation. We conclude that TGF $\beta_{1}$ activates c-Jun via the MEKKI/p38 MAP kinase pathway and influences cytoskeletal organization. These finding may provide a link between TGF $\beta_{\text {I }}$ and the metastatic behavior of cancers.
\end{abstract}

\section{Findings}

The transforming growth factor pathway plays a central role in cellular proliferation, recognition, differentiation, apoptosis and specification of developmental fate, during embryogenesis as well as in mature tissues $[1,2]$. Nearly thirty members have been described in human, many orthologs are known in other vertebrates. Four are known in Caenorhabditis elegans and seven in Drosophila melanogaster. The family is divided into three subfamilies. One subfamily contains of the bone morphogenetic proteins (BMP) plus the growth and differentiaion factors (GDF). The second family consists of the transforming growth factor $\beta$ and activin and nodal proteins. The last family comprises of ligand antagonists such as inhibin- $\alpha$ [3].

TGF $\beta$ signaling generally has a negative effect on cell growth. Inactivation of this pathway contributes to tumorigenesis. The TGF $\beta$ protein is released as an inactive 'latent' complex, comprising a TGF $\beta$ dimer in a non-covalent complex with two prosegments, to which one of several 'latent TGF $\beta$-binding proteins' is often linked. This latent complex represents an important safeguard against 'inadvertent' activation, and may stabilize and target latent TGF $\beta$ to the extracellular matrix, where it is seques- 
tered. The matrix thus acts as a reservoir from which TGF $\beta$ can readily be recruited without the need for new synthesis.

The secretion of TGF $\beta$ as a latent complex necessitates the existence of a regulated activation process, which is most probably mediated through the activities of proteases that preferentially degrade the TGF $\beta$ prosegments and thereby release the highly stable, active TGF $\beta$ dimer. Because plasmin activates latent TGF $\beta$ and plasminogen is converted into plasmin at sites of cell migration and invasion; it is assumed that endothelial and tumor cells are exposed to active TGF $\beta$.

TGF $\beta$ signaling is mediated by a heterotetrameric complex of two trans-membrane receptor serine/threonine kinases, containing a type II ligand binding receptor (TGF $\beta$-RII) and a type I signaling receptor (TGF $\beta$-RI). Smads 2 and 3 are direct substrates of TGF $\beta$-RI and, together with the common mediator, Smad4, play key roles as cytoplasmic signaling mediators. Although the Smad pathway has received much attention in the past years, it is now appreciated that the activated receptor complex can also signal through other pathways, such as those involving the mitogen-activated protein kinases (MAPKs), phosphoinositol-3 kinase (PI3K), and PP2A/p70s6K, though the molecular details of this coupling are still obscure. The relative importance and interplay of these various pathways in the changing responses of cells to TGF $\beta$ are just beginning to be probed [4].

In mammal cells, there are three TGF $\beta$ s, TGF $\beta_{1}, \mathrm{TGF}_{2}$ and $\mathrm{TGF}_{3}$, which are encoded by different genes and which all function through the same receptor system. Of these, $\mathrm{TGF} \beta_{1}$ is most frequently upregulated in tumor cells and is the focus of most studies on the role of TGF $\beta$ in tumorigenesis.

The integrin family of cell adhesion molecules mediates cellular contacts to the extracellular matrix (ECM) or cell counter receptors, thereby regulating development, cell motility, cell polarity, cell growth and survival [5]. Ligand binding to integrins leads to integrin clustering and recruitment of actin filaments and signaling proteins to the cytoplasmic domain of integrins, referred to as focal complexes when they are still nascent and in the process of forming, or focal adhesions (FAs) when they have matured into larger complexes. The formation of cell adhesion complexes assures substrate adhesion as well as targeted location of Actin filaments and signaling components. Cell adhesion complexes are also essential for establishing cell polarity, directed cell migration, and maintaining cell growth and survival $[6,7]$.
The integrin-actin cytoskeleton connection is highly dynamic and is differentially regulated in different locations of the cell. At the leading edge of migrating cells, integrins bind the ECM, recruit the actin cytoskeleton and initiate local reorganization of the actin network, promoting different types of membrane protrusion. At the rear of the cell, integrins detach from the ECM, dissolve the link to the cytoskeleton and are, at least partially, recycled to the front of the cell.

Signaling pathways, which depend on localized integrin activation have also been reported; this is essential for the reorientation of the microtubular network and the directed movement of cells. Complexity is added by the fact that integrin-associated molecules are multifunctional. Integrin-linked actin binding proteins attach to signaling molecules and function as platforms, bringing kinases and substrates together. Integrin-bound signaling molecules, on the other hand, bind to actin binding proteins, enforcing the integrin-cytoskeleton connection. As it turns out for integrin-linked kinase (ILK), such adapter function might be even more important in vivo than the kinase function demonstrated in vitro.

The integrin $\alpha_{V} \beta_{6}$ is expressed principally on epithelial cells [8] where it has been shown to be a receptor for RGD and non-RGD sites in ligands [9]. It is demonstrated that the mature form of TGF $\beta_{1}$ binds to and activates of $\alpha_{V} \beta_{6}$ integrin [10]. Among others, binding of mature TGF $\beta_{1}$ to $\alpha_{\mathrm{v}} \beta_{6}$ integrin resulted in an enhanced immobilization and phosphorylation of proteins, which are associated with focal adhesions $[10,11]$. Surprisingly, stimulation with mature TGF $\beta_{1}$ leads to upregulation of c-Jun in $\mathrm{TGF} \beta_{1}$ sensitive cells [10]. We therefore sought to determine if mature TGF $\beta_{1}$ activates c-Jun via MEKK1/p38 and if this activation may influence cytoskeletal reorganization.

Here, we show that binding of mature TGF $\beta_{1}$ recruits the mitogen-activated protein kinase kinase kinase 1 (MEKK1), a mediator of c-Jun activation, and the extracellular signaling-regulated kinase-1 (Erk1) to focal adhesions. In addition, the p21-activated kinase 1 (PAK1) is associated with focal adhesions and differentially phosphorylated upon stimulation with mature TGF $\beta_{1}$. We conclude that TGF $\beta_{1}$ activates c-Jun via the MEKK1/p38 MAP kinase pathway and influences cytoskeletal organization. These finding may provide a link between TGF $\beta_{1}$ and metastatic behavior of cancers.

Crosstalk between integrins and growth factor receptors are an important signaling mechanism to provide specificity during normal development and pathological processes in vascular biology. Evidence from several model systems demonstrates the physiological importance of the coordination of signals from growth factors and the extra- 

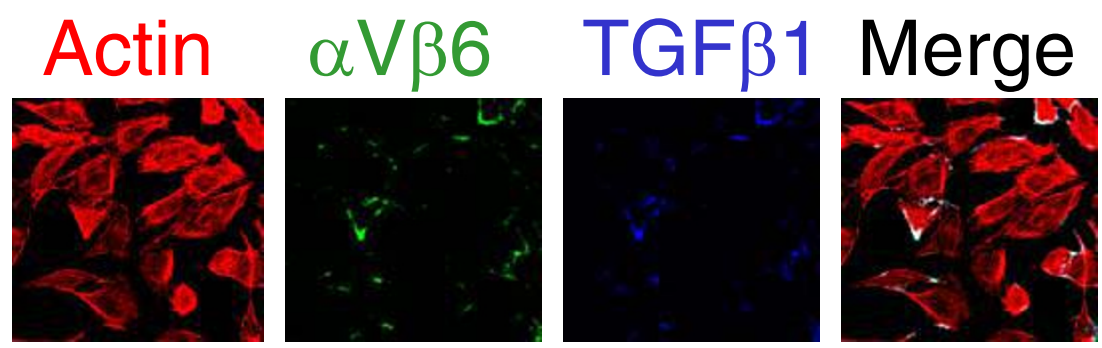

\section{SW48}
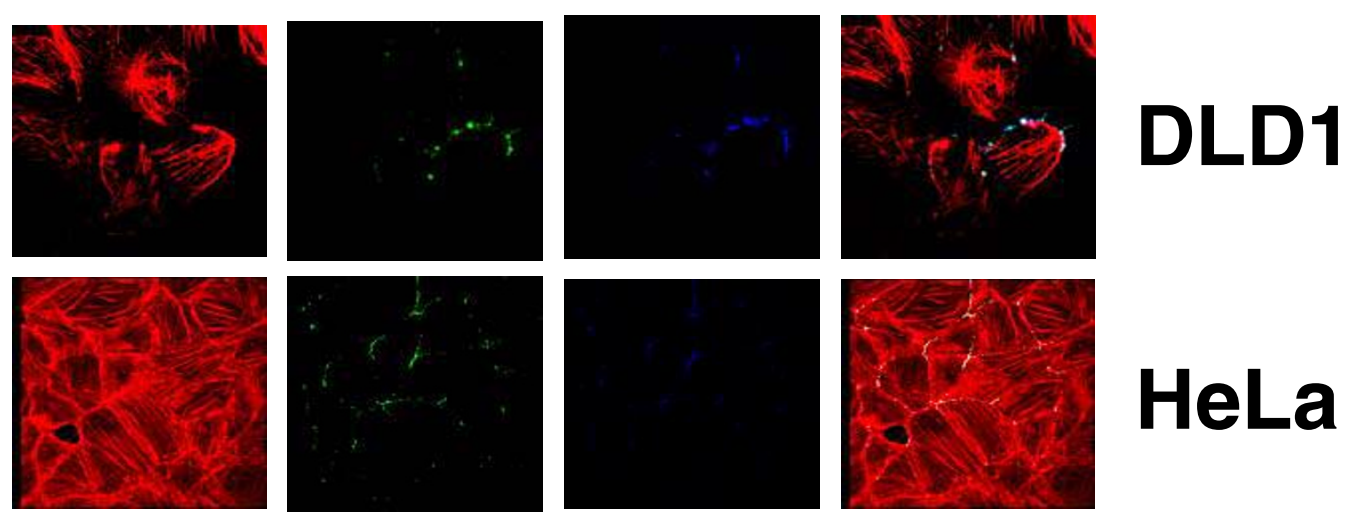

\section{HeLa}
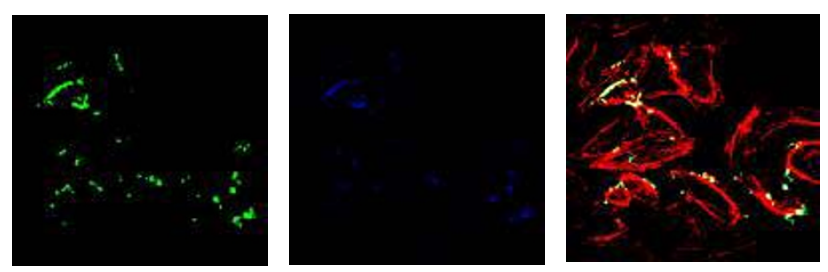

\section{Keratinocytes}

\section{Figure I}

Colocalization of TGF $\beta_{I}, \alpha_{\mathbf{v}} \beta_{6}$ integrin and the cytoskeleton. 10,000 cells(SW48, DLDI, HeLa, keratinocytes) were cultured on glass coverslips in DMEM supplemented with $17 \%$ of heat inactivated fetal bovine serum and stimulated with $10 \mathrm{nM}$ of mature TGF $\beta_{\text {I }}$ (from R\&D Systems) for ten minutes. After preparation of the cytoskeletal fraction by Triton-X100 extraction [10], slides were stained using Alexa Fluor 680 goat anti-mouse lgG (Molecular Probes, Eugene, OR) for actin (sc-8432, Santa Cruz), Alexa Fluor 488 donkey anti-rabbit lgG (Molecular Probes) for $\alpha_{\gamma} \beta_{6}$ integrin (sc-6617 and sc-6632), and Alexa

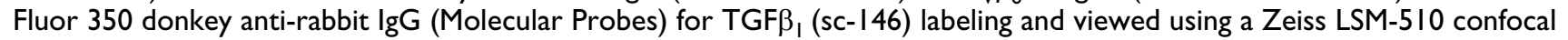
microscope [10]. Magnification $1000 \times$.

cellular matrix to support cell proliferation, migration, and invasion in vivo [12-14]. Several examples of crosstalk between these two important classes of receptors indicate that integrin ligation is required for growth factor-induced biological processes [15]. Furthermore, integrins can directly associate with growth factor receptors, thereby regulating the capacity of integrin/growth factor receptor complexes to propagate downstream signaling $[10,11,16]$.

We have demonstrated that mature TGF $\beta_{1}$ colocalizes with $\alpha_{V} \beta_{6}$ integrin in Panc- 1 cells [10]. To further support our initial findings, we assayed for colocalization between
TGF $\beta_{1}, \alpha_{\mathrm{V}} \beta_{6}$ integrin and the F-actin filaments of the cytoskeleton in SW48, DLD1, HeLa cells as well as keratinocytes. Cells were stimulated with $10 \mathrm{nM}$ of mature TGF $\beta_{1}$. After preparation of the cytoskeletal fraction by Triton-X100 extraction $[10,17,18]$, slides were stained using Alexa Fluor 680 goat anti-mouse IgG (Molecular Probes, Eugene, OR) for Actin, Alexa Fluor 488 donkey anti-rabbit IgG (Molecular Probes) for $\alpha_{\mathrm{V}} \beta_{6}$ integrin, and Alexa Fluor 350 donkey anti-rabbit IgG (Molecular Probes) for TGF $\beta_{1}$ labeling [10]. As shown in Figure 1, in $\operatorname{TGF}_{1}, \alpha_{V} \beta_{6}$ integrin and the F-Actin filaments of the cytoskeleton colocalize after stimulation with mature $\mathrm{TGF} \beta_{1}$ in all cell lines used. These results further support 

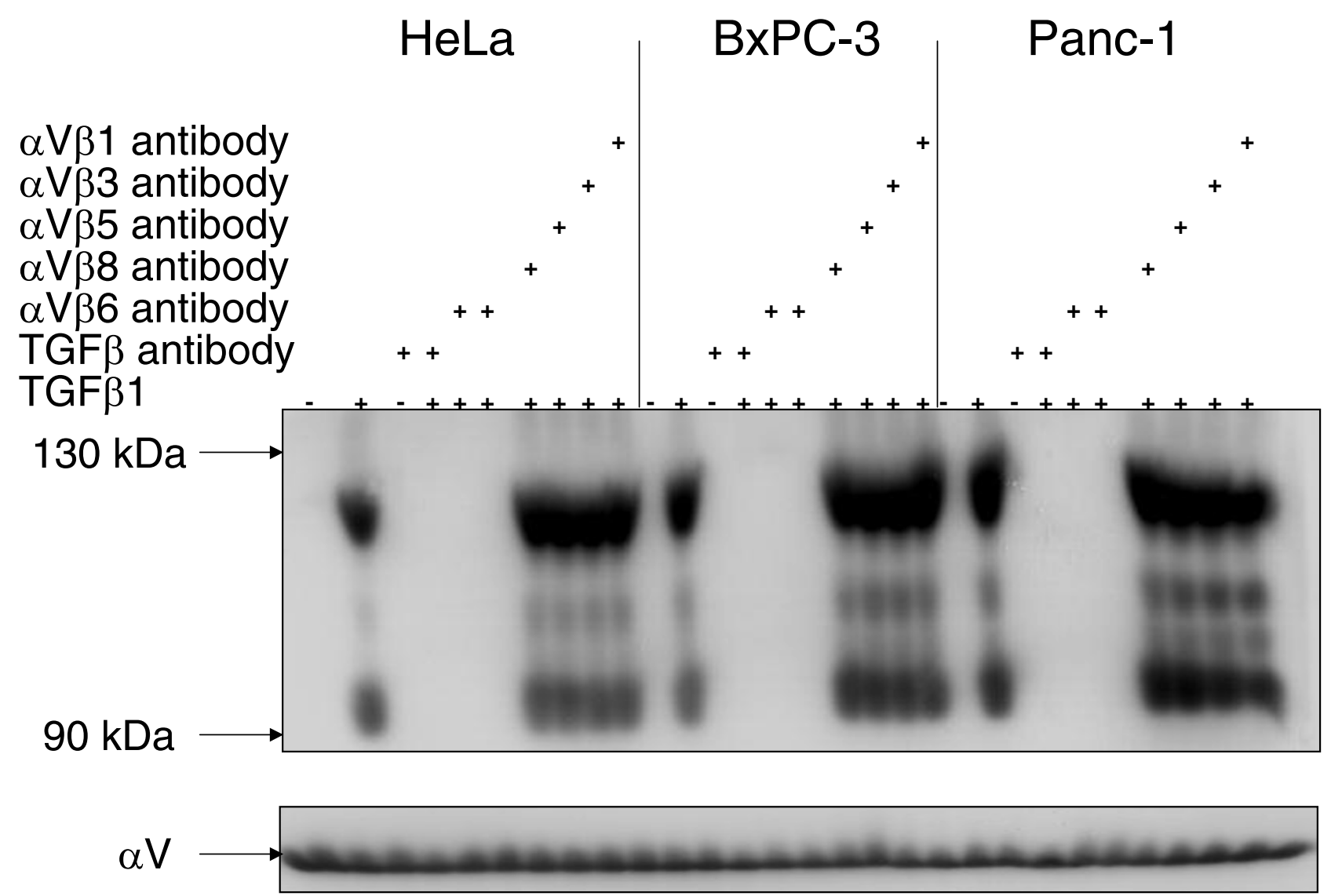

\section{Figure 2}

Phosphorylation and immobilization of proteins associated with focal adhesions. Cytoskeletally anchored $\alpha_{\mathrm{V}} \beta_{6}$ was immunoprecipitated after TGF $\beta_{1}$ stimulation ( $10 \mathrm{nM}$ for 10 minutes) followed by Western analysis with antibodies against tyrosine-phosphorylated proteins or $\alpha_{V}$ integrin. In part the cells were preincubated with $\alpha_{V^{-}}$and $\beta_{8^{-}}, \beta_{6^{-}}, \beta_{5^{-}}, \beta_{3^{-}}$, and $\beta_{1^{-}}$antibod-

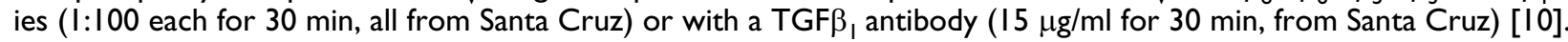

our initial findings that mature TGF $\beta_{1}$ is a ligand for $\alpha_{\mathrm{V}} \beta_{6}$ integrin.

Adhesion to the extracellular matrix is an important process that controls cell shape change, migration, proliferation, survival, and differentiation. Upon adhesion, integrins and a selective group of cytoskeletal and signaling proteins are recruited to cell matrix contact sites where they link the actin cytoskeleton to the ECM and mediate signal transduction between the intracellular and extracellular compartments [18].

We demonstrated that mature TGF $\beta_{1}$ induces an enhanced immobilization and phosphorylation of proteins, which are associated with focal adhesions, in TGF $\beta_{1}$ sensitive cells [10]. In order to provide further evidence for the specificity of this interaction, we preincubated cells with antibodies against $\alpha_{V} \beta_{8}, \alpha_{V} \beta_{6^{\prime}} \alpha_{V} \beta_{5}, \alpha_{V} \beta_{3}$, and $\alpha_{V} \beta_{1}$ integrins prior to stimulation with mature TGF $\beta_{1}$. Consistent with our initial report, preincubation with $\alpha_{v} \beta_{6}$ antibodies abolished the TGF $\beta_{1}$-induced tyrosine phosphorylation of proteins, which are associated with focal adhesions (Figure 2). In sum, we could confirm our initial findings that mature TGF $\beta_{1}$ is a ligand for $\alpha_{\mathrm{V}} \beta_{6}$ integrin and that this association results in immobilization and tyrosine phosphorylation of proteins, which are associated with focal adhesions, in TGF $\beta_{1}$ sensitive cells.

Paxillin is a multi-domain protein that localizes in cultured cells primarily to sites of cell adhesion to the 


\section{$\alpha$ TGF $\beta$ RII}

\section{BAPTA-AM}

$+$

\section{Cytochalasin D}

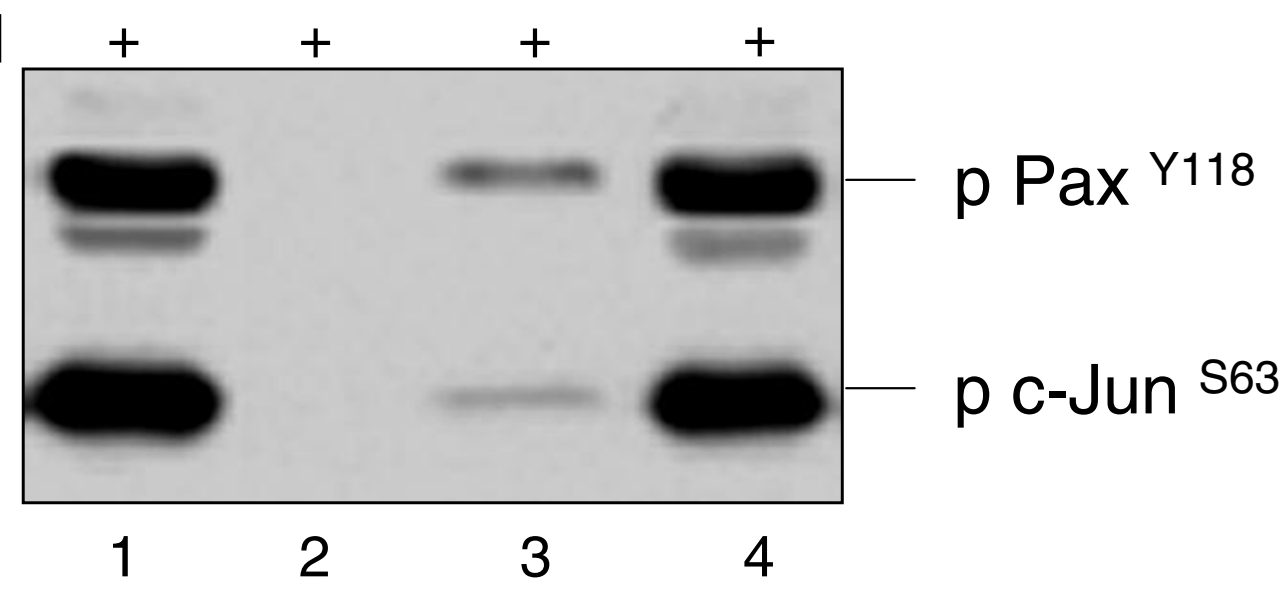

\section{Figure 3}

Paxillin and c-Jun are associated with focal adhesions. BxPC- 3 cells were stimulated with $10 \mathrm{nM}$ of mature TGF $\beta_{1}$ for ten minutes followed by preparation of the Triton-X100 nonsoluble fraction and precipitation with $\alpha_{v} \beta_{6}$ integrin antibodies. The precipitate was then re-precipitated with anti-FAK antibodies (sc-1688) and analyzed with antibodies against p-Paxillin Yll8 (254I, Cell Signaling) and p-c-Jun ${ }^{563}$ (962I, Cell Signaling). In part, the cells were preincubated with a TGF $\beta$-RII antibody (Santa Cruz), BAPTA-AM and Cytochalasin D, respectively [10].

extracellular matrix (ECM) called focal adhesions [6]. Focal adhesion proteins including paxillin also serve as a point of convergence for signals resulting from stimulation of various classes of growth factor receptors $[19,20]$. It binds to many proteins that are involved in effecting changes in the organization of the actin cytoskeleton, which are necessary for cell motility events associated with embryonic development, wound repair and tumor metastasis. These range from structural proteins such as vinculin and actopaxin, that bind actin directly to regulators of actin cytoskeletal dynamics, such as the ARF GAP, PKL, the exchange factor PIX and the p21-activated kinase, PAK. These proteins serve as modulators/effectors of the ARF and RHO GTPase families [6,7]. In our assays, Paxillin was found to be phosphorylated at $Y^{118}$ after stimula- tion and associated with focal adhesions after stimulation of BxPC-3 cells with mature TGF $\beta_{1}$ (Figure 3 ). This phosphorylation was dependent on an intact cytoskeleton as well as free intracellular calcium (Figure 3).

Both paxillin and focal adhesion kinase (FAK) undergo phosphorylation during integrin-mediated cell adhesion and during stimulation by a variety of mitogens and growth factors $[6,7]$. There is growing evidence that integrins function as mechanotransducers and that the regulation of cellular responses to mechanical stimuli is coordinated by the complex of cytoskeletal proteins that associate with the cytoplasmic domains of integrin molecules [17]. In cultured cells, FAK and paxillin undergo tyrosine phosphorylation in response to periods 


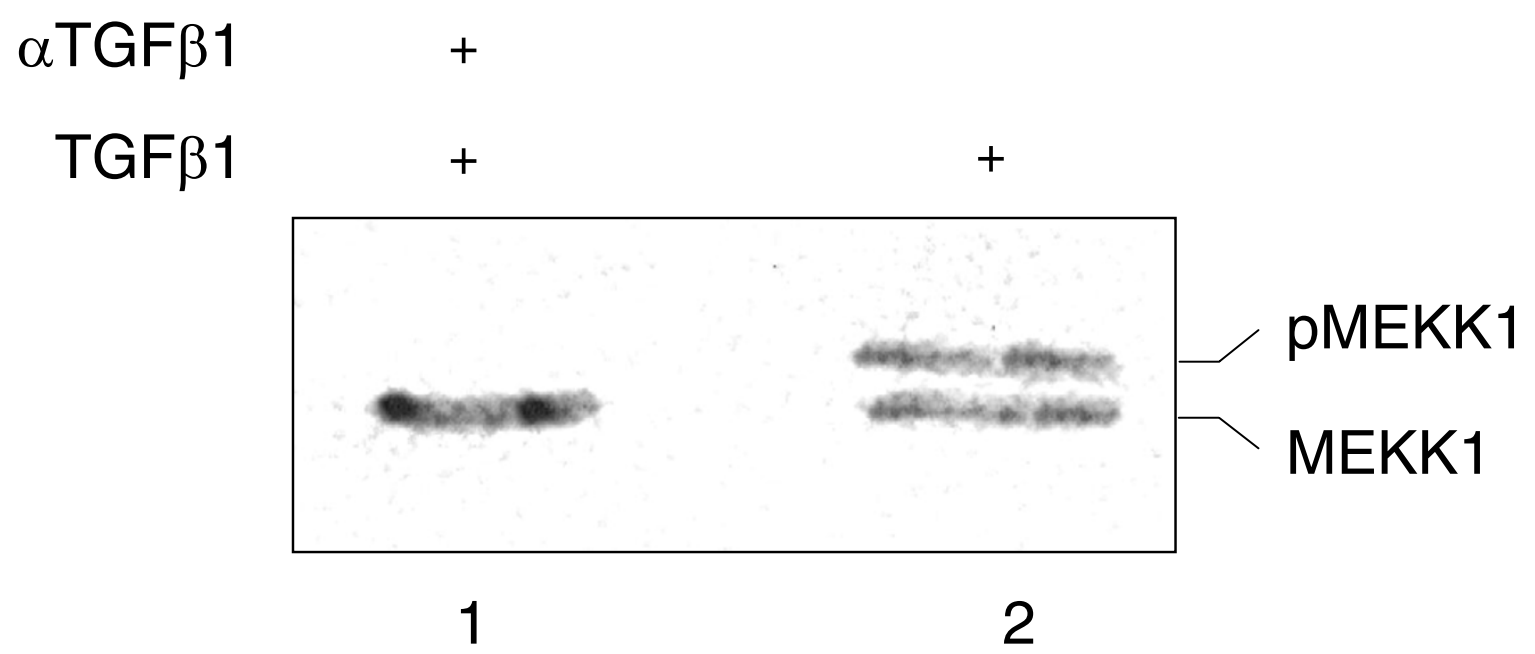

\section{Figure 4}

MEKKI is associated with focal adhesions. BxPC- 3 cells were stimulated with $10 \mathrm{nM}$ of mature TGF $\beta$, for ten minutes followed by preparation of the Triton-X100 nonsoluble fraction and precipitation with $\alpha_{\mathrm{V}} \beta_{6}$ integrin antibodies. The precipitate was then re-precipitated with anti-FAK antibodies (sc-I688) and analyzed with a MEKKI antibody (sc-448). In part, the cells were preincubated with a TGF $\beta$, antibody [10].

of repetitive mechanical strain $[17,18]$. In a number of cultured cell types, including endothelial cells and airway smooth muscle cells, cyclic mechanical strain has been shown to induce the alignment of actin filaments along the axis perpendicular to the force vector $[17,18]$. Paxillin and FAK were identified as integration points in signaling proximal to integrins and growth-factor receptors. We speculate that the conversion of growth-factor and adhesion signaling occurs on the actin filaments. The cytoplasmic domains of integrins and receptors for growth factors and cytokines are closely associated with the ends of the cytoskeleton; reorganization of microfilaments may influence the environment of these integrins and receptors, thereby facilitating the triggering of a signaling pathway. The mechanisms are obscure.
Activation of paxillin/FAK by integrins and growth factors is important for efficient signal propagation by pathways including paxillin that lead to the regulation growth and differentiation. A similar role for FAK was described in the control of growth factor- and integrin-mediated cell migration in fibroblasts [21]. This suggests that paxillin/ FAK have a general role in linking integrins/growth-factor receptors with the regulation of cytoskeletal changes that controls various biological processes in different cells. Paxillin and FAK have been proposed to play an integral role in these strain-induced morphological changes.

Reorganization of the cytoarchitecture regulates signaling pathways including the mobilization of intracellular calcium, activation of tyrosine kinases, Ras, extracellular sig- 


\section{$\begin{array}{rr}\alpha \operatorname{TGF} \beta 1 & + \\ \operatorname{TGF} \beta 1 & +\end{array}$}

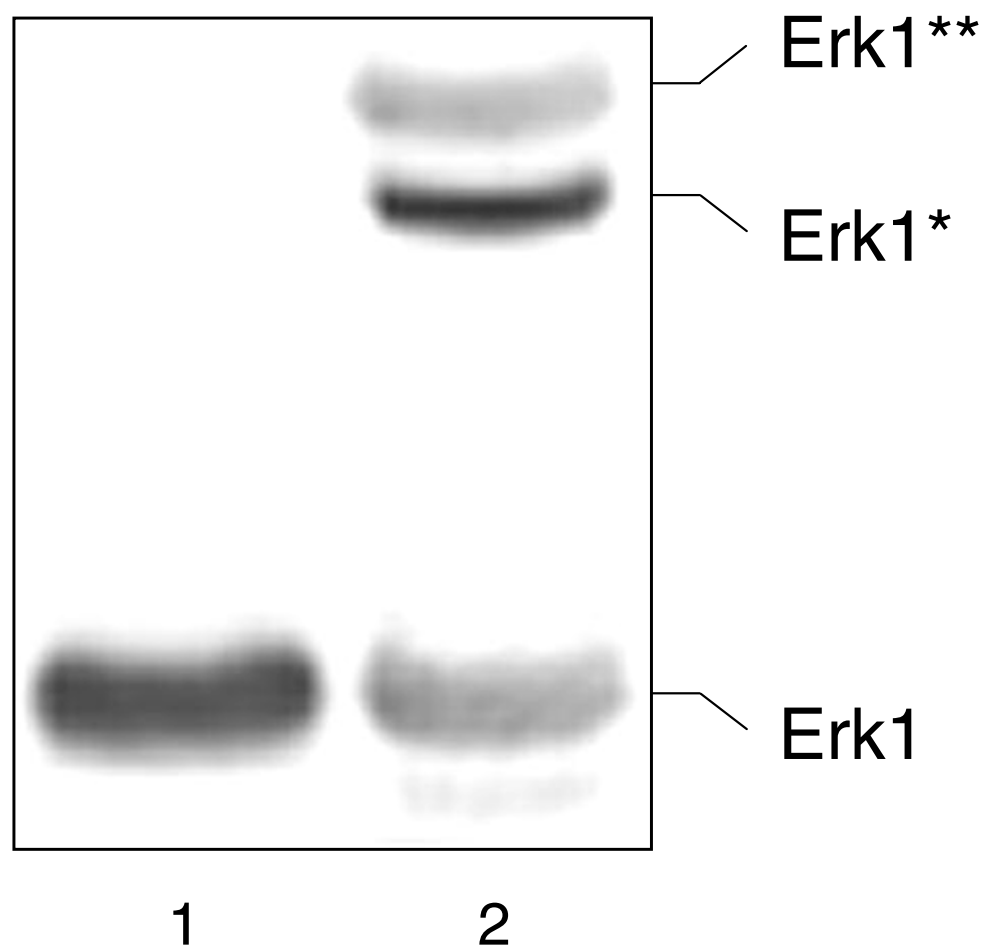

\section{Figure 5}

Erk I is associated with focal adhesions. BxPC-3 cells were stimulated with $10 \mathrm{nM}$ of mature TGF $\beta$, for ten minutes followed by preparation of the Triton-X100 nonsoluble fraction and precipitation with $\alpha_{V} \beta_{6}$ integrin antibodies. The precipitate was then re-precipitated with anti-FAK antibodies (sc-1688) and analyzed with an Erk I antibody (sc-93). In part, the cells were preincubated with a TGF $\beta_{\text {I }}$ antibody [10].

nal-regulated kinase (ERK), and c-Jun $\mathrm{NH}_{2}$-terminal kinase (JNK). Consistent with the activation of signaling pathways, specific transcription factors are activated by cytoskeletal restructuring $[10,11,17]$. We stimulated BxPC-3 cells with $10 \mathrm{nM}$ of mature TGF $\beta_{1}$, prepared the Triton-X100 nonsuluble fraction, precipitated with $\alpha_{V} \beta_{6}$ integrin antibodies followed by re-precipitation with FAK antibodies. Our assays revealed that MEKK1 and c-Jun are phosphorylated and associated with focal adhesions after stimulation of BxPC-3 cells with mature TGF $\beta_{1}$ (Figures 3 and 4). Our findings are in part supported by Verrecchia et al showing that TGF $\beta$ induces c-Jun and JunB [22]. In addition, our finding that MEKK1 associates with focal adhesions finds support in the report from Cuevas et al [23]. Cuevas et al show evidence that MEKK1 colocalizes with focal adhesions in adhering MEKK1\% fibroblasts reconstituted with EGFP-MEKK1 [23]. However, this is the first report that c-Jun is associated with the cytoskeleton, whilst phosphorylated.

MEKK1 is absolutely required for cellular responses, which alter the integrity of the microtubule cytoskeleton and cell shape; MEKK1 is the MAPK kinase kinase regulating the JNK pathway $[24,25]$. The significance for a cytoskeletal immobilization of c-Jun is not known. We also detected Erk1 associated with focal adhesions in BxPC-3 cells, stimulated with $10 \mathrm{nM}$ of mature TGF $\beta_{1}$ (Figure 5). Most strikingly, we observed two bands for the phosphorylated form of Erk1. These bands are not visible after incubation with phosphatases (data not shown). 


\section{PP2 + $\quad+$}

\section{PD98059 +}
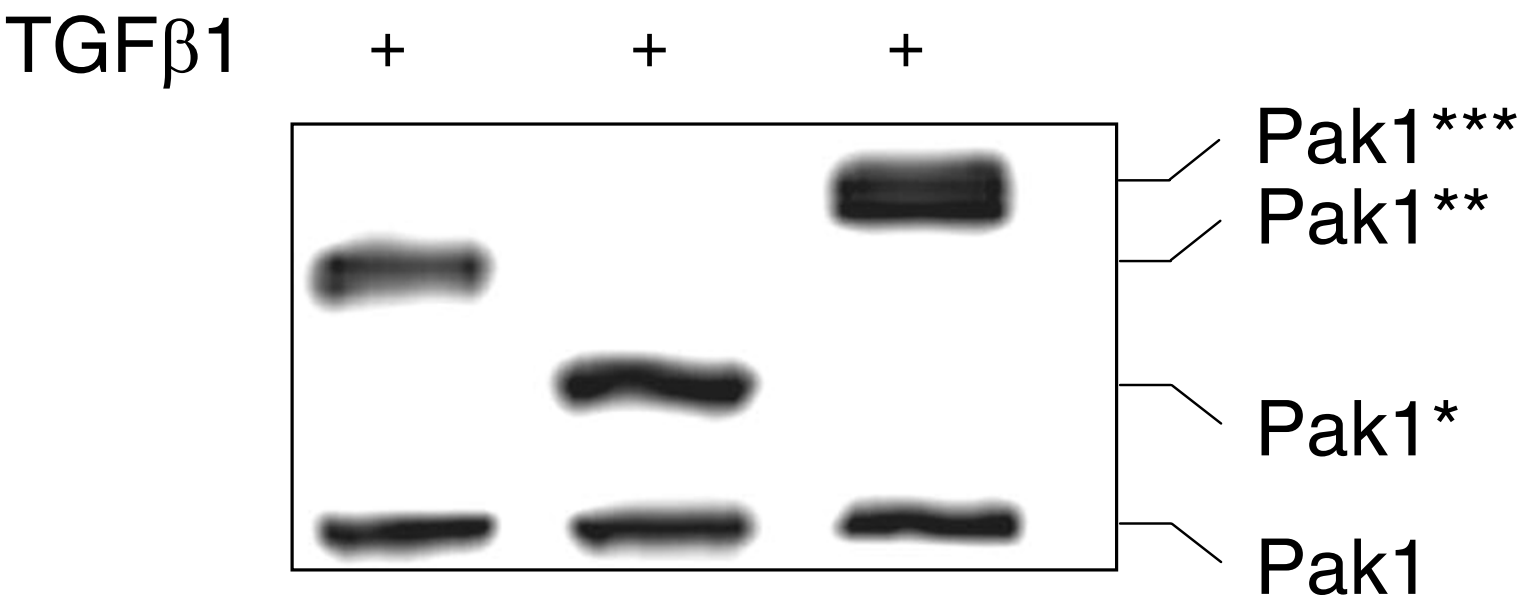

$1 \quad 2 \quad 3$

\section{Figure 6}

PakI is associated with focal adhesions. BxPC- 3 cells were stimulated with $10 \mathrm{nM}$ of mature TGF $\beta_{1}$ for ten minutes followed by preparation of the Triton-X100 nonsoluble fraction and precipitation with $\alpha_{v} \beta_{6}$ integrin antibodies. The precipitate was then reprecipitated with anti-FAK antibodies (sc-1688), followed by re-precipitation with anti-phosphos (ab9334, Abcam), anti-phosphoThr (ab2286), and analyzed with a PakI antibody (7I-9300, Zymed). In part, the cells were preincubated with 50 $\mu \mathrm{M}$ PP2 (Calbiochem), and $50 \mu \mathrm{M}$ PD98059 (Calbiochem), respectively [10].

The mitogen-activated protein kinase, referred to as MAP kinase or extracellular signal-regulated kinase (ERK), is a serine/threonine protein kinase whose activity is rapidly stimulated by a number of external stimuli through mechanisms mediated by tyrosine kinase-encoded receptors, non-receptor type tyrosine kinases, and G protein-coupled receptors. MAP kinase is activated by phosphorylation on its threonine and tyrosine residues, a process, which is carried out by a dual-specificity protein kinase, MAP kinase kinase. MAP kinases have been shown to phosphorylate and thereby activate many well studied regulatory proteins located in diverse cellular compartments, including nuclear transcriptional factors [26]. A function of MAP kinases may therefore be to provide a link between transmembrane signaling and the nucleus.
There is much evidence that MAP kinases may be involved in cell growth and differentiation by phosphorylating and thereby activating nuclear transcriptional factors [27].

Meanwhile, there are many compelling examples of gene expression induced by adhesive interactions with ECM [28-30]. Thus, MAP kinase may play a pivotal role in adhesion-dependent gene activation through the integrinmediated signaling pathways. The fact that MAP kinase is activated by both, growth factor- and integrin-mediated signals, suggests that these two signaling pathways converge at this or upstream points. However, resolving the nature and degree of interactions between integrinand growth factor-mediated signaling pathways, and their relative contributions, must await more complete defini- 
tion and understanding of integrin-mediated growth-factor-induced signal transduction pathways.

Hyperactive Erk may phosphorylate Tau in an abnormal fashion. Tau hyperphosphorylation by abnormaly active Erk is demonstrated in neuroblastoma cells, suggesting that abnormak Erk activity function as apoptosis inducing kinase [31]. Additional factors may compensate this effect, leading to resistance to apoptosis, multidrug resistance, or metastatic behavior of cancers [32,33]. Support for this speculation comes from another report showing that the family of p21 activated kinases (PAK) is involved in actin cytoskeleton organization $[34,35]$.

The p21-activated kinases (PAKs) are serine/threonine protein kinases that bind to and, in some cases, are stimulated by activated forms of the small GTPases, Cdc42 and Rac [36]. The PAK family of kinases has been implicated in control of actin filaments and in cell motility. Targets for PAK are likely to be involved in migration, including myosin light chain kinase (MLCK) and LIM kinase. MLCK phosphorylates MLC, and this phosphorylation has been shown to be important in regulating actin cytoskeletal dynamics. In addition, PAK phosphorylates and activates LIMK, which in turn phosphorylates and inhibits the actin severing protein cofilin, thus promoting filament assembly. The PAK interacting guanine nucleotide exchange factor PIX, the ARF GTPase activating protein PKL, and the adaptor protein Nck, are also mediators of Rho GTPase signaling; they form a complex with PAK to regulate the actin cytoskeleton and stimulate focal complex formation through paxillin interactions. G protein coupled receptor kinase interacting protein (GIT1) links PAK to FAK and results in focal contact turnover, while another protein, p95 APP 1, of the GIT family, has been implicated in membrane recycling during locomotion, suggesting a role of GIT family members in cell motility [37]. Thus, PAK plays an important role in Racdriven cell motility through several different signaling cascades.

The Erk-MAP kinase, including PAK, PI3K, and MEKK1, have been linked to motility [38]. Rac can regulate several different pathways through different effectors. Rac activates PI3K and AKT independent of JNK, and activates the MEKK-JNK cascade independent of PAK. In addition to the Rac-MEKK-JNK and the ERK cascades, PI3K-AKT has also been shown to promote cell migration.

We found that Pak1 is associated with focal adhesions upon stimulation of BxPC-3 cells with $10 \mathrm{nM}$ of mature $\mathrm{TGF}_{1}$ (Figure 6). The Src family kinase inhibitor 4amino-5-(4-chloro-phenyl)-7-(t-butyl)pyrazolo- [3,4-d]pyrimidine (PP2) significantly reduced the phosphorylation level of Pak1 compared with the MEK1 inhibitor
PD98059. The effect of the MEK1 inhibitor on the Pak1 phosphorylation is striking because Pak1 is considered upstream of MEK1/Erk [39]. It is possible that other signaling molecules mediate a crosstalk between the two pathways. Notably, the src-inhibitor PP2 partially reduced the Pak1 phosphorylation level. Blocking of Pak activity is considered a so called "signal therapy for Ras-induced cancers" [40,41].

As is clear from this study, there is a lot that remains to be understood about the integrin-mediated signal transduction elicited by mature TGF $\beta_{1}[42,43]$. Further studies will provide us with answers in the near future that will shed light on many of the remaining mysteries of the TGF $\beta$ puzzle.

\section{Author's contributions}

CS performed all assays and drafted the manuscript. KL provided suggestions for its finalization. Both authors read and approved the final manuscript.

\section{Acknowledgements}

CS acknowledges support from the German Research Foundation and is indebted to Martin Paul Kracklauer and Jonathan A.F. Hannay for critically reading the manuscript.

\section{References}

I. Rusten Tor Erik, Cantera Rafael, Kafatos Fotis C. and Barrio Rosa: The role of TGF $\{$ beta\} signaling in the formation of the dorsal nervous system is conserved between Drosophila and chordates. Development 2002, I 29:3575-3584.

2. Tudela C, Formoso MA, Martinez T, Perez R, Aparicio M, Maestro C, Del Rio A, Martinez E, Ferguson M and Martinez-Alvarez C: TGFbeta3 is required for the adhesion and intercalation of medial edge epithelial cells during palate fusion. Int J Dev Biol 2002, 46:333-336.

3. Massague J, Blain SW and Lo RS: TGFbeta signaling in growth control, cancer, and heritable disorders. Cell 2000, 103:295-309.

4. Shi $Y$ and Massague J: Mechanisms of TGF-beta signaling from cell membrane to the nucleus. Cell 2003, I I 3:685-700.

5. Marsden $M$ and DeSimone DW: Integrin-ECM interactions regulate cadherin-dependent cell adhesion and are required for convergent extension in Xenopus. Curr Biol 2003, I 3: I | 82- I I 91 .

6. Giancotti FG and Ruoslahti E: Integrin signaling. Science 1999, 285: 1028-1032.

7. Giancotti FG: A structural view of integrin activation and signaling. Dev Cell 2003, 4: |49-I5I.

8. Lohr M, Trautmann B, Gottler M, Peters S, Zauner I, Maier A, Kloppel $G$, Liebe $S$ and Kreuser ED: Expression and function of receptors for extracellular matrix proteins in human ductal adenocarcinomas of the pancreas. Pancreas 1996, I 2:248-259.

9. Kraft S, Diefenbach B, Mehta R, Jonczyk A, Luckenbach GA and Goodman SL: Definition of an unexpected ligand recognition motif for alphav beta6 integrin. J Biol Chem 1999, 274: 1979-1985.

10. Kracklauer MP, Schmidt $C$ and Sclabas GM: TGFbeta I signaling via alphaVbeta6 integrin. Mol Cancer 2003, 2:28.

II. Lohr M, Schmidt C, Ringel J, Kluth M, Muller P, Nizze H and Jesnowski $\mathrm{R}$ : Transforming growth factor-betal induces desmoplasia in an experimental model of human pancreatic carcinoma. Cancer Res 2001, 6 1:550-555.

12. Jones JI, Gockerman A, Busby WH, Jr, Wright G and Clemmons DR: Insulin-like growth factor binding protein I stimulates cell migration and binds to the \{alpha\}5 5 beta\} I integrin by means of its Arg-Gly-Asp sequence. PNAS 1993, 90:10553-10557. 
13. Li Jing, Lin Meei-Lih, Wiepz Gregory J., Guadarrama Arturo G. and Bertics Paul J.: Integrin-mediated migration of murine B82L fibroblasts is dependent on the expression of an intact Epidermal Growth Factor receptor. J Biol Chem 1999, 274: II209-II2I9.

14. Wang Jian Feng, Zhang Xue-Feng and Groopman Jerome E.: Stimulation of beta I integrin induces tyrosine phosphorylation of Vascular Endothelial Growth Factor receptor-3 and modulates cell migration. J Biol Chem 200I, 276:41950-4I 957.

15. Eliceiri Brian P.: Integrin and growth factor receptor crosstalk. Circ Res 200I, 89: I I04-III0.

16. Takagi Junichi, Beglova Natalia, Yalamanchili Padmaja, Blacklow Stephen C. and Springer Timothy A.: Definition of EGF-like, closely interacting modules that bear activation epitopes in integrin beta subunits. PNAS 200I, 98: III75-1 II80.

17. Schmidt C, Pommerenke H, Durr F, Nebe B and Rychly J: Mechanical stressing of integrin receptors induces enhanced tyrosine phosphorylation of cytoskeletally anchored proteins. J Biol Chem 1998, 273:508I-5085.

18. Pommerenke H, Schmidt C, Durr F, Nebe B, Luthen F, Muller P and Rychly J: The mode of mechanical integrin stressing controls intracellular signaling in osteoblasts. J Bone Miner Res 2002, 17:603-6II.

19. Leopoldt D, Yee H. F., Jr., Saab S and Rozengurt E: Tyrosine phosphorylation of pl25(Fak), pl30(Cas), and paxillin does not require extracellular signal-regulated kinase activation in Swiss 3T3 cells stimulated by bombesin or platelet-derived growth factor. J Cell Physiol 2000, 183:208-220.

20. Guvakova MA and Surmacz E: The activated insulin-like growth factor I receptor induces depolarization in breast epithelial cells characterized by actin filament disassembly and tyrosine dephosphorylation of FAK, Cas, and paxillin. Exp Cell Res 1999, 25 I:244-255.

21. McKean David M., Sisbarro Lila, Ilic Dusko, Kaplan-Alburquerque Nihal, Nemenoff Raphael, Weiser-Evans Mary, Kern Michael J. and Jones Peter Lloyd: FAK induces expression of Prx I to promote tenascin-C-dependent fibroblast migration. J Cell Biol 2003, 161:393-402.

22. Verrecchia F, Tacheau C, Schorpp-Kistner M, Angel $P$ and Mauviel A: Induction of the AP-I members c-Jun and JunB by TGF-beta/ Smad suppresses early Smad-driven gene activation. Oncogene 200I, 20:2205-22II.

23. Cuevas Bruce D., Abell Amy N., Witowsky James A., Yujiri Toshiaki, Johnson Nancy Lassignal, Kesavan Kamala, Ware Marti, Jones Peter L. Weed Scott A., DeBiasi Roberta L., Oka Yoshitomo, Tyler Kenneth L. and Johnson Gary L.: MEKKI regulates calpain-dependent proteolysis of focal adhesion proteins for rear-end detachment of migrating fibroblasts. EMBO 」 2003, 22:3346-3355.

24. Li YS, Shyy JY, Li S, Lee J, Su B, Karin M and Chien S: The Ras-JNK pathway is involved in shear-induced gene expression. Mol Cell Biol 1996, 16:5947-5954.

25. Xia Y, Makris C, Su B, Li E, Yang J, Nemerow GR and Karin M: MEK kinase $\mathbf{I}$ is critically required for c-Jun $\mathbf{N}$-terminal kinase activation by proinflammatory stimuli and growth factorinduced cell migration. Proc Natl Acad Sci U S A 2000, 97:5243-5248.

26. Blenis J: Signal transduction via the MAP kinases: proceed at your own RSK. Proc Natl Acad Sci U S A 1993, 90:5889-5892.

27. Johnson Gary L. and Lapadat Razvan: Mitogen-activated protein kinase pathways mediated by ERK, JNK, and p38 protein kinases. Science 2002, 298:1911-1912.

28. Mahoney Tracey S., Weyrich Andrew S., Dixon Dan A., Mclntyre Thomas, Prescott Stephen M. and Zimmerman Guy A.: Cell adhesion regulates gene expression at translational checkpoints in human myeloid leukocytes. PNAS 200I, 98: I0284-10289.

29. Brizzi Maria Felice, Defilippi Paola, Rosso Arturo, Venturino Mascia, Garbarino Giovanni, Miyajima Atsushi, Silengo Lorenzo, Tarone Guido and Pegoraro Luigi: Integrin-mediated adhesion of endothelial cells induces JAK2 and STAT5A activation: role in the control of c-fos gene expression. Mol Biol Cell 1999, 10:3463-347|

30. Kutz Stacie M., Hordines John, McKeown-Longo Paula J. and Higgins Paul J.: TGF-\{beta\} I-induced PAI-I gene expression requires MEK activity and cell-to-substrate adhesion. J Cell Sci 200I, | | 4:3905-39|4.
31. Guise S, Braguer D, Carles G, Delacourte A and Briand C: Hyperphosphorylation of tau is mediated by ERK activation during anticancer drug-induced apoptosis in neuroblastoma cells. $J$ Neurosci Res 2001, 63:257-267.

32. Juhasz M, Nitsche B, Malfertheiner P and Ebert MP: Implications of growth factor alterations in the treatment of pancreatic cancer. Mol Cancer 2003, 2:5.

33. Keleg S, Buchler P, Ludwig R, Buchler MW and Friess H: Invasion and metastasis in pancreatic cancer. Mol Cancer 2003, 2: 14.

34. Holly SP and Blumer KJ: PAK-family kinases regulate cell and actin polarization throughout the cell cycle of Saccharomyces cerevisiae. / Cell Biol 1999, I 47:845-856.

35. Eby JJ, Holly SP, van Drogen F, Grishin AV, Peter M, Drubin DG and Blumer KJ: Actin cytoskeleton organization regulated by the PAK family of protein kinases. Curr Biol 1998, 8:967-970.

36. Edwards DC, Sanders LC, Bokoch GM and Gill GN: Activation of LIM-kinase by PakI couples Rac/Cdc42 GTPase signalling to actin cytoskeletal dynamics. Nat Cell Biol 1999, I:253-259.

37. Garcia Arguinzonis Maisa I., Galler Annette B., Walter Ulrich, Reinhard Matthias and Simm Andreas: Increased spreading, Rac/p2 Iactivated kinase (PAK) activity, and compromised cell motility in cells deficient in vasodilator-stimulated phosphoprotein (VASP). J Biol Chem 2002, 277:45604-456I0.

38. Fanger Gary R., Johnson Nancy Lassignal and Johnson Gary L.: MEK kinases are regulated by EGF and selectively interact with Rac/Cdc42. EMBO J. | 997, | 6:496|-4972.

39. Eblen Scott T., Slack Jill K., Weber Michael J. and Catling Andrew D.: Rac-PAK Signaling Stimulates Extracellular Signal-Regulated Kinase (ERK) Activation by Regulating Formation of MEKI-ERK Complexes. Mol Cell Biol 2002, 22:6023-6033.

40. He H, Hirokawa Y, Manser E, Lim L, Levitzki A and Maruta H: Signal therapy for RAS-induced cancers in combination of AG 879 and PPI, specific inhibitors for ErbB2 and Src family kinases, that block PAK activation. Cancer J 2001, 7:191-202.

4I. King AJ, Wireman RS, Hamilton M and Marshall MS: Phosphorylation site specificity of the Pak-mediated regulation of Raf-I and cooperativity with Src. FEBS Lett 200I, 497:6-14.

42. Roberts Anita B. and Wakefield Lalage M.: The two faces of transforming growth factor \{beta\} in carcinogenesis. PNAS 2003 , 100:862|-8623.

43. Yang Yaw-Ching, Piek Ester, Zavadil Jiri, Liang Dan, Xie Donglu, Heyer Joerg, Pavlidis Paul, Kucherlapati Raju, Roberts Anita B. and Bottinger Erwin P.: Hierarchical model of gene regulation by transforming growth factor \{beta\}. PNAS 2003, 100:10269-10274.

Publish with Bio Med Central and every scientist can read your work free of charge

"BioMed Central will be the most significant development for disseminating the results of biomedical research in our lifetime. "

Sir Paul Nurse, Cancer Research UK

Your research papers will be:

- available free of charge to the entire biomedical community

- peer reviewed and published immediately upon acceptance

- cited in PubMed and archived on PubMed Central

-yours - you keep the copyright
BioMedcentral 